\title{
A study of commercial vehicle brake judder transmission using multi-body dynamic analysis
}

\author{
K Hussain $^{1 *}$, S H Yang ${ }^{2}$, and A Day ${ }^{1}$ \\ ${ }^{1}$ School of Engineering, Design and Technology, University of Bradford, Bradford, Republic of West Yorkshire, UK \\ ${ }^{2}$ Hyundai Motor Company, Seoul, Republic of Korea
}

The manuscript was received on 16 August 2005 and was accepted after revision for publication 2 October 2006.

DOI: 10.1243/1464419JMBD23

\begin{abstract}
Braking-induced forced vibration, known as brake judder in road vehicles, causes dissatisfaction to drivers and passengers and also damage and possible early failure in components and systems. In this paper, the transmission of judder vibration from the point of generation (the brake friction pair) through the vehicle structure to the driver is investigated for the particular case of a heavy commercial vehicle. The investigation uses a computer simulation multi-body dynamic model based on the automatic dynamic analysis of mechanical systems software to identify any characteristics of the vehicle suspension design that might influence the vibration transmission from the wheel to the driver.

The model uses a simplified rigid chassis and cab to lump the chassis parameters, so that the investigation can focus on the front axle/suspension design, which is a beam axle leaf spring arrangement, and the rear axle/suspension assembly, which is a tandem axle bogie design. Results from the modelling indicate that brake judder vibration is transmitted to the chassis of the vehicle through a leaf spring 'wind-up' mode and a 'walking' mode associated with the rear tandem axle. Of particular interest is the longitudinal vibration transmitted through the chassis, since this creates a direct vibration transmission path to the cab and driver. The simulation results were compared with the previously published experimental work on the same design of commercial vehicle, and agreement between the predicted and the measured vibration characteristics and frequencies was found.

It is concluded that the rear suspension design parameters could affect the transmission of brake judder vibration to the cab and driver and that a tandem rear axle offers some design opportunity to control the transmission of brake judder vibrations from the wheel to the cab and driver. Given that brake judder has so far defied all attempts to eliminate completely from vehicle brake systems, this is potentially an important opportunity.
\end{abstract}

Keywords: brake, judder, vibration, commercial vehicle, multi-body, dynamic, prediction, simulation

\section{INTRODUCTION}

Customer demands for higher vehicle performance and larger load carrying capacity places increased duty levels on the braking system, which in turn can lead to increases in brake noise and vibration. Almost all road vehicles demonstrate some brakingrelated noise and/or vibration, and how well this

* Corresponding author: School of Engineering, Design and Technology, University of Bradford, Bradford, West Yorkshire BD7 IDP, UK.email: k.hussain1@bradford.ac.uk can be predicted in the vehicle-design process determines how well a vehicle performs on the road in terms of noise, vibration, and harshness and ultimately from the customer's point of view.

Brake judder has been studied for many years by many automotive manufacturers and brake suppliers. It is a mechanically induced vibration arising from small imperfections in the rotating part of the brake interacting with the stationary parts. Such imperfections may be due to manufacturing inaccuracies or be generated by wear or thermal effects in the brake rotor and/or stator [1], which then lead 
to the phenomenon of brake torque variation (BTV) as the wheel rotates under braking conditions. Large amplitudes of low-frequency vibration felt in the vehicle body and driver/passenger contact items such as the steering wheel or seats during braking are a direct result of brake judder.

BTV is known to be influenced by small component changes such as friction material [2], but so far it has proved impossible to design a vehicle to be completely free from brake judder throughout its working life. For this reason, the reduction of transferred vibration to the driver or passengers would possibly be more effective than any attempt to avoid BTV altogether. The logic for this is derived from the known fact that all vehicles have a certain level of BTV but not all drivers complain of brake judder, thus indicating that the vibration is not a problem if the driver or passengers cannot sense its existence. Therefore, vehicles could be designed to be free from the effects of brake judder by minimizing the vibration transmission to the vehicle and hence to the driver, rather than by attempting to remove the cause.

The manufacture of commercial vehicles has many of the characteristics of low volume production, with many model variants representing the range of duty levels and operational usage that the vehicle might be used for. It is not possible to fit the same brake system to all vehicles in the product range and meet either usage requirements or legislative imperatives. A judder-free brake system on one vehicle might not be judder-free on other model variants of even the same vehicle: Gassmann and Engel [3] showed that dynamic brake/disc geometry changes during braking could generate BTV and tested the three vehicles with similar front suspensions which generated considerably different judder sensitivities.

Kim et al. $[\mathbf{4}, \mathbf{5}]$ carried out a sensitivity analysis of a commercial vehicle chassis system to reduce shimmy and judder vibration. They showed experimentally that at the steering wheel, vibrations caused by brake judder had a diverse frequency range depending on harmonic orders of wheel rotational frequency. The basic judder frequency in their study was the fourth-order component of the wheel rotational frequency.

During braking, drivers or passengers may feel vibrations through airborne or structure-borne transmission and thus brake noise and vibration could be assessed in terms of perception, which is usually based on frequency and amplitude. In terms of frequency, brake judder is a low-frequency brake vibration, of perhaps $50-100 \mathrm{~Hz}$, whereas brake squeal is a high frequency noise in the region of $1-6 \mathrm{kHz}$ and is independent of the vehicle speed $[\mathbf{1}, \mathbf{5}-\mathbf{9}]$.

Brake judder has been investigated extensively in the context of the foundation brake alone. As the comfort of commercial vehicles becomes more important, a greater interest in brake judder in the commercial vehicle industry is emerging. Advances in computer technology and the increasing availability of multi-body dynamic analysis tools have made the study of various vehicle dynamics issues possible, e.g. the more realistic modelling of subparts in a vehicle such as leaf springs, bushes, steering wheel mechanism, shock absorbers, and tyres has become of great importance in a virtual vehicle design. Rahnejat [10] and Blundell and Hartley [11] have described the applicability of multi-body dynamics tools such as automatic dynamic analysis of mechanical system (ADAMS) to a variety of vehicle dynamic and vibration problems.

In this paper, multi-body dynamic modelling techniques are used for the purpose of investigating vibration transmission from the wheel brake through the axle and suspension system to the chassis and cab of a commercial vehicle. Results from the simulations have been compared with the previously published data relating to a similar vehicle.

\section{MULTI-BODY DYNAMICS VEHICLE MODELS}

The investigation was based on a $6 \times 4$ articulated commercial vehicle tractor unit manufactured by the Hyundai Motor Company (HMC). Two multibody dynamics models were constructed using the commercial ADAMS software: first a two-dimensional simplified vehicle model to investigate the overall vibration characteristics of the vehicle and second a three-dimensional vehicle model which included a more detailed model of the rear suspension system. The purpose of the first model was to demonstrate vibration transmission from the wheels to the cab and driver, and the purpose of the second model was to demonstrate how the rear suspension design contributed to vibration transmission to the chassis.

\subsection{Model 1: the two-dimensional vehicle model}

Figure 1 shows the two-dimensional model, based on the data from the manufacturer's data sheet.

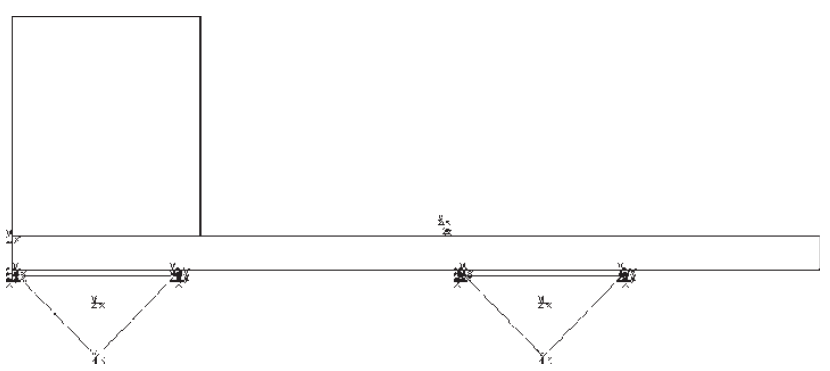

Fig. 1 Two-dimensional model for the $6 \times 4$ tractor vehicle 
Table 1 Specifications for the two-dimensional vehicle model

\begin{tabular}{llll}
\hline Sprung mass & $M$ & $23340 \mathrm{~kg}$ & GVW condition \\
Sprung mass moment of inertia & $J$ & $3.1747 \mathrm{E} 10 \mathrm{~kg} \mathrm{~mm}^{2}$ & \\
Distance between front axle and CG & $x_{\mathrm{c}}$ & $2885.6 \mathrm{~mm}$ & GVW and kerb weight condition \\
Distance between rear axle and CG & $y_{\mathrm{c}}$ & $1089 \mathrm{~mm}$ \\
Unsprung mass on front suspension & $M_{\mathrm{tf}}$ & $715 \mathrm{~kg}$ & $1500 \mathrm{~kg}$ \\
Unsprung mass on rear suspension & $M_{\mathrm{tr}}$ & $6.9473 \mathrm{E} 7 \mathrm{~kg} \mathrm{~mm}^{2}$ & Kerb weight condition \\
Front unsprung mass moment of inertia & $J_{\mathrm{tf}}$ & $\left(0 \mathrm{~mm}, 456.8 \mathrm{~mm}^{2}\right.$ & \\
Front unsprung mass CG point & $\left(x_{\mathrm{c}}, y_{\mathrm{c}}\right)$ & $1.4581 \mathrm{E} 8 \mathrm{~kg} \mathrm{~mm}$ & \\
Rear unsprung mass moment of inertia & $J_{\mathrm{tr}}$ & $(3700 \mathrm{~mm}, 456.8 \mathrm{~mm})$ & \\
Rear unsprung mass CG point & $\left(x_{\mathrm{c}}, y_{\mathrm{c}}\right)$ & $6840 \mathrm{~kg}$ \\
Sprung mass & $M$ & $1.4316 \mathrm{E} 10 \mathrm{~kg} \mathrm{~mm}^{2}$ & $1548.4 \mathrm{~mm}$ \\
Sprung mass moment of inertia & $J$ & $973.1 \mathrm{~mm}$ & \\
Distance between front axle and CG & $x_{\mathrm{c}}$ & & \\
Distance between rear axle and CG & $y_{\mathrm{c}}$ & &
\end{tabular}

The two rear axles were modelled as one, positioned at the mid-point between the two axles. The spring stiffnesses were set at $1706 \mathrm{~N} / \mathrm{mm}$ for the rear suspension and $378.5 \mathrm{~N} / \mathrm{mm}$ for the front suspension. The value of the horizontal leaf spring stiffness was set at 23 times that of vertical leaf spring stiffness based on manufacturer's data.

The front and rear wheel brake and suspension components were modelled by two rigid links forming a connection between the centre of the tyre contact point with the road surface and the two end points of the leaf spring attached to the chassis.

The connection between the lowest point and the road was made through a spring element equivalent to the vertical stiffness of the tyre, constrained to have vertical motion only. Specifications of the two-dimensional vehicle model are given in Table 1. For the gross vehicle weight (GVW) condition, the additional weight was applied at the fifth wheel position.

The two-dimensional vehicle model was constrained to two-dimensional planar motion by three planar joints. One joint was located on the centre of gravity (CG) point of the vehicle sprung part, and the other two were placed on the front and rear tyre contact point with the road surface; these simulated the point of instantaneous centre between the tyre and the road with a superimposed cyclic variation in braking torque associated with judder.

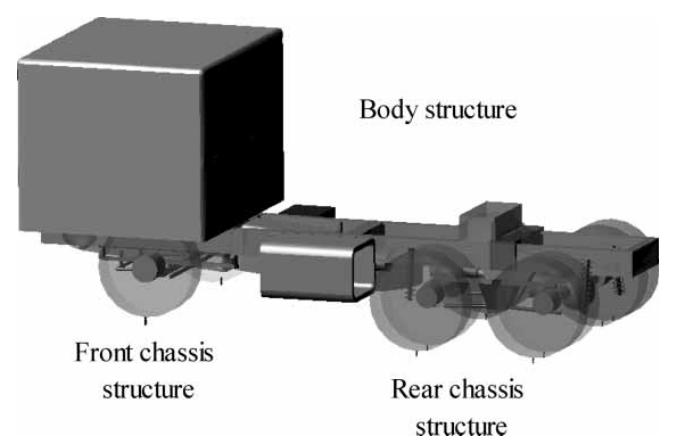

Fig. 2 Three-dimensional vehicle model

\subsection{Model 2: the three-dimensional vehicle model}

The three-dimensional vehicle model shown in Fig. 2 comprises the vehicle body structure, the front suspension system, and the rear suspension system.

The body structure part of the model was based on CAD data supplied by the manufacturer. It was modelled as a series of connected rigid component models including the geometric features of the vehicle chassis, cab, fuel tank, spare wheel, and fifth wheel at the correct positions so that the weight distribution was represented correctly.

The front suspension was a beam axle leaf spring suspension system, as shown in Fig. 3. The front leaf spring was modelled as a cantilever beam spring of uniform section using the 'discrete flexible links'

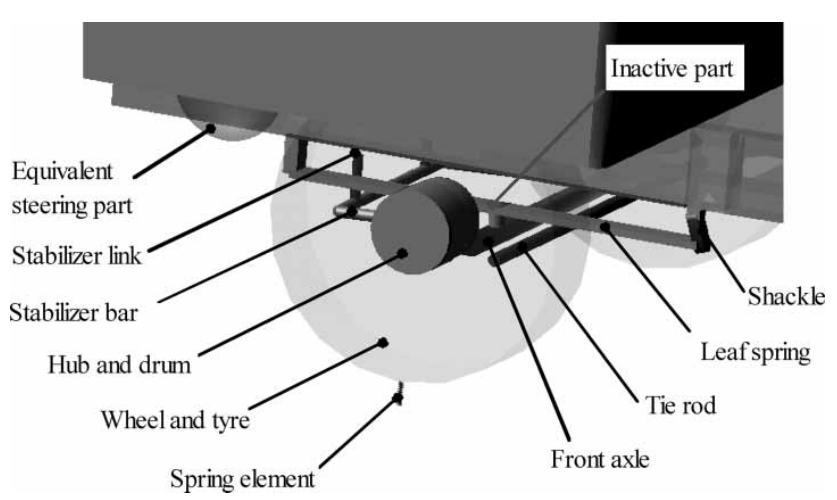

Fig. 3 Front chassis suspension system structure

Table 2 Front leaf spring specifications

\begin{tabular}{ll}
\hline Total spring length & $1500 \mathrm{~mm}$ \\
Front spring length & $750 \mathrm{~mm}$ \\
Rear spring length & $750 \mathrm{~mm}$ \\
Spring width & $90 \mathrm{~mm}$ \\
Spring thickness & $25.12 \mathrm{~mm}$ \\
Clamped stiffness & $378.5 \mathrm{~N} / \mathrm{mm}$ \\
Unclamped stiffness & $338.31 \mathrm{~N} / \mathrm{mm}$ \\
\hline
\end{tabular}




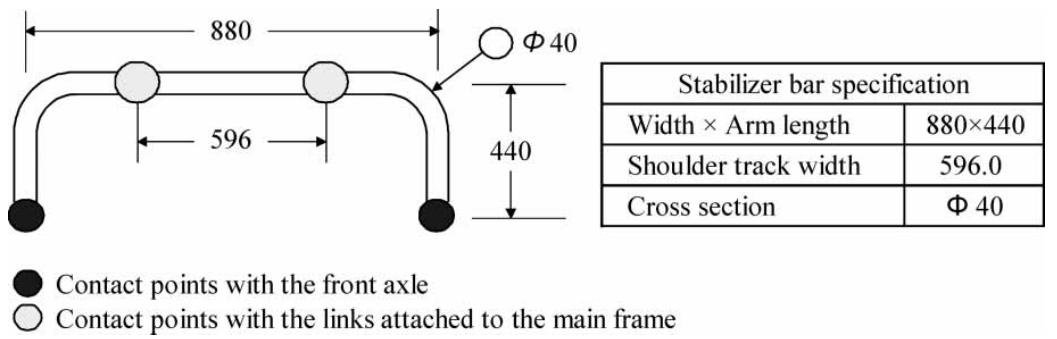

Fig. 4 Stabilizer bar specifications (dimensions in $\mathrm{mm}$ )

tool in ADAMS. The flexible part on each side had ten beam elements, which were linked together by beam forces. The width, the length, the unclamped stiffness, and the clamped stiffness of the spring are shown in Table 2.

The front end of the leaf spring was attached to the main frame via a revolute joint whose rotational axis was parallel with the vehicle transverse axis. The rear end of the leaf spring was connected to the shackle via a revolute joint and the shackle was attached to the main frame by another revolute joint. All three joints had the same transverse axial orientation. The front axle was connected to the centre of the leaf spring via a dummy part and a fixed joint as shown in Fig. 3.

The stabilizer bar was modelled as a flexible link with 15 elements, being a U-shaped spring with a circular cross-section. Dimensions and specifications are shown in Fig. 4.

Both ends of the stabilizer bar were connected to the front axle via spherical joints and the two shoulder positions were connected to the stabilizer links in the same way.

The wheel hub and brake drum components were modelled as cylindrical parts to represent the vehicle weight distribution and were attached to the wheel and tyre parts via revolute joints. The wheel and tyre were also modelled as cylindrical parts which were connected to the road via spring elements which had the same radial stiffness as the tyre. The

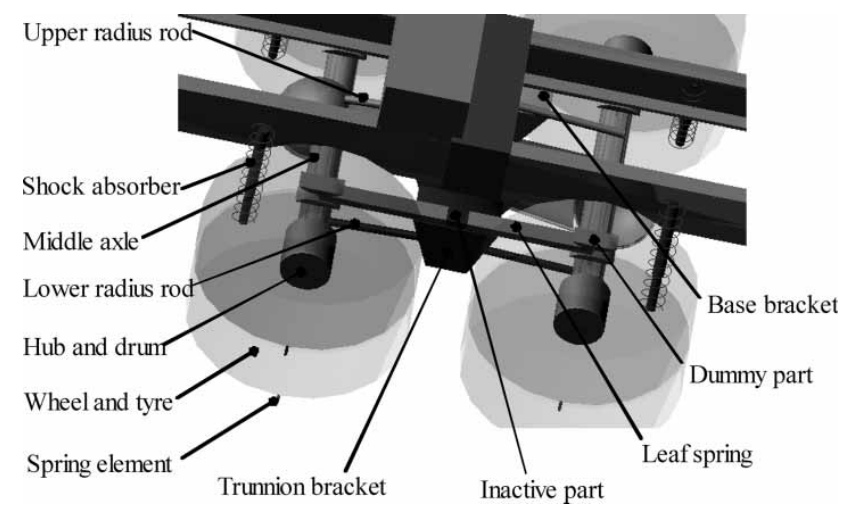

Fig. 5 Rear tandem axle suspension system contact points with the ground were also constrained to move vertically and rotate about the ground contact point in the direction of the vehicle pitch motion using a planar joint and a general motion constraint element, again this simulated the point of instantaneous centre between the tyre and the road with a superimposed cyclic variation in braking torque associated with judder. The steering system was not modelled but its mass was included in that of the vehicle. The rear suspension system of the vehicle was a tandem axle bogie suspension with multi-leaf steel springs, as shown in Fig. 5. The multi-leaf spring was modelled in the same way as the front leaf spring model, i.e. as a cantilever beam spring with a uniform section representing the leaf length and clamped stiffness (Table 3).

The leaf spring length was the distance between the centre-lines of the middle axle and the rear axle. The stiffness change resulting from the spring effective length change during suspension movement was not included. The rear tandem axle suspension structure was modelled as shown in Fig. 5. Each axle had three radius rods: one of

Table 3 Rear leaf spring specifications

\begin{tabular}{ll}
\hline Total spring length & $1300 \mathrm{~mm}$ \\
Front spring length & $650 \mathrm{~mm}$ \\
Rear spring length & $650 \mathrm{~mm}$ \\
Spring width & $90 \mathrm{~mm}$ \\
Spring thickness & $37.3 \mathrm{~mm}$ \\
Clamped stiffness & $1706 \mathrm{~N} / \mathrm{mm}$ \\
Unclamped stiffness & $2167 \mathrm{~N} / \mathrm{mm}$ \\
\hline
\end{tabular}

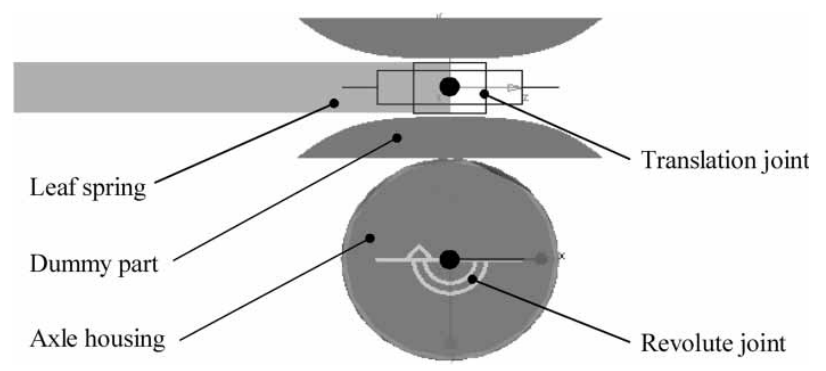

Fig. 6 Joint mechanism between the axle and the leaf spring 
Table 4 Mass and geometric properties of the vehicle

\begin{tabular}{|c|c|c|c|}
\hline Parts & Variable & Data & Condition \\
\hline \multirow[t]{3}{*}{ Front unsprung } & CG & $(-0.59 \mathrm{~mm},-3.09 \mathrm{E}-3 \mathrm{~mm},-365.44 \mathrm{~mm})$ & $\begin{array}{l}\text { Kerb weight } \\
\text { condition/GVW condition }\end{array}$ \\
\hline & Moment of inertia & $1.4261 \mathrm{E} 10 \mathrm{~kg} \mathrm{~mm}^{2}$ & \\
\hline & Weight & $705.56 \mathrm{~kg}$ & \\
\hline \multirow[t]{3}{*}{ Rear unsprung } & $\mathrm{CG}$ & $(3689.85 \mathrm{~mm}, 0.3537 \mathrm{~mm},-513.56 \mathrm{~mm})$ & \\
\hline & Moment of inertia & $2.2082 \mathrm{E} 10 \mathrm{~kg}$ & \\
\hline & Weight & $1538.37 \mathrm{~kg}$ & \\
\hline \multirow[t]{3}{*}{ Sprung parts } & $\mathrm{CG}$ & $(1525.14 \mathrm{~mm}, 17.55 \mathrm{~mm},-40.28 \mathrm{~mm})$ & Kerb weight condition \\
\hline & Moment of inertia & $3.8990 \mathrm{E} 10 \mathrm{~kg} \mathrm{~mm}^{2}$ & \\
\hline & Weight & $6820.91 \mathrm{~kg}$ & \\
\hline \multirow[t]{3}{*}{ Total vehicle } & $\mathrm{CG}$ & $(1773.75 \mathrm{~mm},-13.14 \mathrm{~mm},-145.91 \mathrm{~mm})$ & \\
\hline & Moment of inertia & $6.1215 \mathrm{E} 10 \mathrm{~kg} \mathrm{~mm}^{2}$ & \\
\hline & Weight & $9064.84 \mathrm{~kg}$ & \\
\hline \multirow[t]{3}{*}{ Sprung parts } & $\mathrm{CG}$ & $(2879.94 \mathrm{~mm},-5.13 \mathrm{~mm}, 74.53 \mathrm{~mm})$ & GVW condition \\
\hline & Moment of inertia & $2.3451 \mathrm{E} 11 \mathrm{~kg} \mathrm{~mm}^{2}$ & \\
\hline & Weight & $23320.91 \mathrm{~kg}$ & \\
\hline \multirow[t]{3}{*}{ Total vehicle } & $\mathrm{CG}$ & $(2849.18 \mathrm{~mm},-4.66 \mathrm{~mm}, 27.0 \mathrm{~mm})$ & \\
\hline & Moment of inertia & $2.5673 \mathrm{E} 11 \mathrm{~kg} \mathrm{~mm}^{2}$ & \\
\hline & Weight & $25564.84 \mathrm{~kg}$ & \\
\hline
\end{tabular}

which was an upper radius rod connected to the frame cross member and the other two were symmetrically connected to the trunnion brackets of the leaf spring base bracket on each side. Spherical joints were used to connect each radius rod to its counterpart. In order to describe the leaf spring motion on each axle, a dummy element was used between the leaf spring element and the axle as shown in Fig. 6.

A translational joint was applied between the leaf spring element and the dummy part at the leaf spring end point in order for the leaf spring element to have sliding motion on the axle in the longitudinal direction, and a revolute joint was used between the dummy element and the axle at the axle centre to provide rotational motion to the axle centre. This

Table 5 Natural frequencies of the simple vehicle model in kerb weight condition

\begin{tabular}{lccc}
\hline Mode & $\begin{array}{l}\text { Natural } \\
\text { frequency } \\
\text { (Hz) kerb } \\
\text { weight }\end{array}$ & $\begin{array}{l}\text { Natural } \\
\text { frequency } \\
\text { (Hz) GVW }\end{array}$ & Mode description \\
\hline 1 & 2.7383 & 1.9607 & $\begin{array}{c}\text { Rotational motion about } \\
\text { tyre-road contact } \\
\text { Bouncing motion of the } \\
\text { sprung part }\end{array}$ \\
3 & 3.9605 & 2.8095 & $\begin{array}{c}\text { Pitching motion of the } \\
\text { vehicle } \\
\text { Vertical motion of the } \\
\text { front unsprung mass } \\
5\end{array}$ \\
6.7105 & 4.4550 & $\begin{array}{c}\text { Vertical motion of the } \\
\text { rear unsprung mass } \\
\text { Rotational motion of } \\
\text { the front unsprung } \\
\text { mass }\end{array}$ \\
7 & 15.7154 & 22.7653 & $\begin{array}{c}\text { Rotational motion of } \\
\text { the front unsprung } \\
\text { mass }\end{array}$ \\
\hline
\end{tabular}

mechanism enabled the leaf spring to slide on the axle and also the axle to rotate about its centre-line.

The leaf spring model was connected to the trunnion bracket via a fixed joint. The trunnion bracket was connected to the base bracket via a revolute joint to rotate freely in the vehicle pitch direction, whereas the base bracket was attached to the cross member with a fixed joint. The hub and drum assembly parts and the wheel and tyre assembly parts were modelled in the same way as those for the front suspension.

The constraint conditions of the middle axle tyres (i.e. on the foremost axle of the tandem axle bogie) were the same as those of the front axle tyres, but the rear wheels (i.e. on the rearmost axle of the tandem axle bogie) had an additional constraint not to rotate about the axle in order for the vehicle model to be kept stationary during simulation. The vehicle parameters are shown in Table 4.

\section{SIMULATION RESULTS}

\subsection{Two-dimensional vehicle model}

Table 5 shows the natural frequencies and the nature of the mode shapes for the two-dimensional vehicle model.

Figure 7 shows the mode shapes of the twodimensional vehicle model. These indicate that the vibration of the sprung part was affected by the vehicle weight conditions, whereas those of the unsprung parts were relatively little affected.

The horizontal spring stiffness was found to make a considerable contribution to the longitudinal vibration behaviour of the vehicle and hence was considered to be potentially a major factor in the transmission of brake judder vibration from the wheels to 


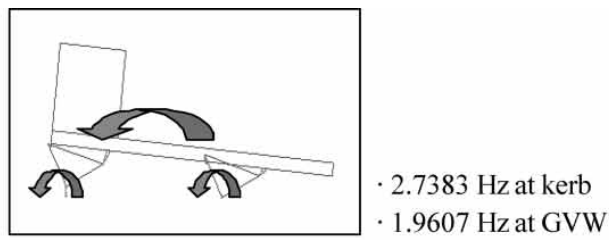

a. First mode shape with natural frequency

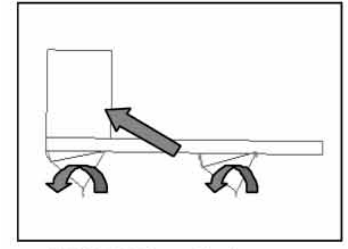

$\cdot 3.9605 \mathrm{~Hz}$ at kerb

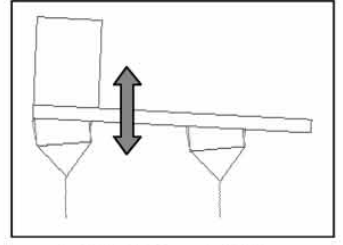

$2.8095 \mathrm{~Hz}$ at GVW

b. Second mode shape with natural frequency

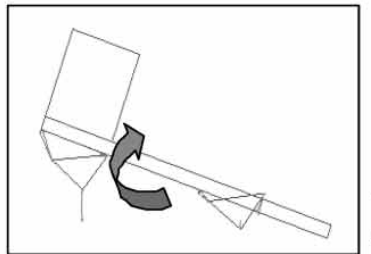

- $6.7105 \mathrm{~Hz}$ at kerb - $4.4550 \mathrm{~Hz}$ at GVW

c. Third mode shape with natural frequency

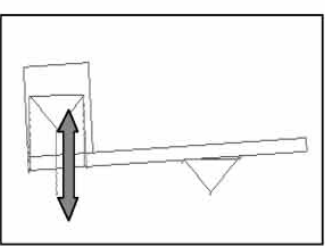

$\cdot 15.7154 \mathrm{~Hz}$ at kerb

- $16.6965 \mathrm{~Hz}$ at GVW

d. Fourth mode shape with natural frequency e. Fifth mode shape with natural frequency

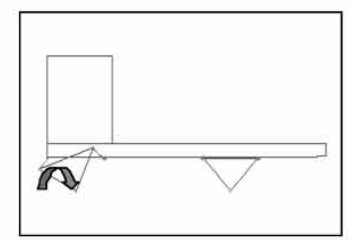

- $40.2383 \mathrm{~Hz}$ at kerb

. $40.4354 \mathrm{~Hz}$ at GVW

f. Sixth mode shape with natural frequency

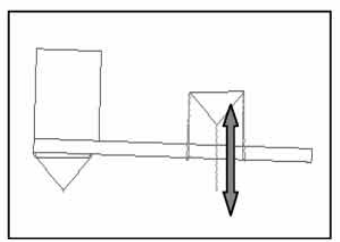

$\cdot 17.0357 \mathrm{~Hz}$ at kerb - $22.7653 \mathrm{~Hz}$ at GVW

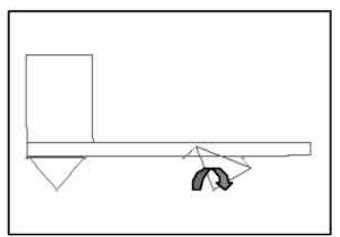

$59.8910 \mathrm{~Hz}$ at kerb - $65.3889 \mathrm{~Hz}$ at GVW

g Seventh mode shape with natural frequency

Fig. 7 Mode shapes of the two-dimensional vehicle model

the cab and driver. From the mode shapes shown in Fig. 7, fourth- and higher-order modes could potentially have some effect on the transmission of brake judder vibration, since they appeared to define the vibration behaviour of unsprung parts.

\subsection{Three-dimensional model results}

The GVW condition of the vehicle model was modelled by a rigid part with the weight difference between the kerb weight and GVW connected to the fifth wheel via a revolute joint. Linear-mode analyses were first carried out, and the natural frequencies and mode shapes of vibration were determined. The predicted frequencies and mode shapes are shown in Table 6 and Fig. 8, respectively.

The rear tandem axle of the vehicle model contributed to a 'wind-up' mode of the rear leaf spring. The mode shapes and natural frequencies indicated that the longitudinal vibrations of the vehicle could be caused by a walking mode $(9.4354 \mathrm{~Hz})$ of the rear tandem axle and the wind-up mode $(20.4552 \mathrm{~Hz})$ of the rear leaf spring. Additionally, because of the short wheel base length, it is possible that a vertical motion of the rear part of the vehicle could generate a longitudinal motion at the cab position. 
Table 6 Natural frequencies related to the low-frequency vibration

\begin{tabular}{|c|c|c|c|}
\hline Number & $\begin{array}{l}\text { Description of the } \\
\text { mode shape }\end{array}$ & $\begin{array}{l}\text { Kerb } \\
\text { weight }(\mathrm{Hz})\end{array}$ & $\begin{array}{l}\text { GVW } \\
(\mathrm{Hz})\end{array}$ \\
\hline $\mathrm{a}$ & $\begin{array}{l}\text { Bouncing mode of the } \\
\text { vehicle front }\end{array}$ & 2.0083 & 1.9055 \\
\hline b & Pitching mode of the vehicle & 5.1329 & 2.2213 \\
\hline $\mathrm{c}$ & $\begin{array}{l}\text { Walking mode of the } \\
\text { tandem axle }\end{array}$ & 10.6473 & 9.4354 \\
\hline $\mathrm{d}$ & $\begin{array}{l}\text { Vertical mode of the } \\
\text { front axle }\end{array}$ & 11.0668 & 11.0681 \\
\hline $\mathrm{e}$ & $\begin{array}{l}\text { Vertical mode of the } \\
\text { tandem axle }\end{array}$ & 16.0098 & 15.8085 \\
\hline $\mathrm{f}$ & $\begin{array}{l}\text { Wind up mode of the } \\
\text { front spring }\end{array}$ & 29.0448 & 20.4552 \\
\hline g & $\begin{array}{l}\text { Wind up mode of the } \\
\text { front spring }\end{array}$ & 47.8517 & 48.3912 \\
\hline
\end{tabular}

The first ride frequencies describing the pitch and bounce motion and the second ride frequencies characterizing the unsprung motion of the front and the rear axles of the vehicle were similar to those obtained from the two-dimensional vehicle model. The three-dimensional vehicle model included the rear tandem axle suspension system, so the effect of the rear tandem axle installation could be determined. A 'wind-up' mode of the rear leaf spring was predicted, which had a lower frequency than the twodimensional vehicle model which did not consider two axles.

\section{COMPARISON WITH THE EXPERIMENTAL DATA}

The predicted results from the two multi-body dynamics models were compared with the published experimental data from Kim [5], who measured vibrations in a similar articulated vehicle tractor unit, weight $44 \mathrm{t}$, decelerating at $0.2-0.3 \mathrm{~g}$ from an initial speed of $90 \mathrm{~km} / \mathrm{h}$. Accelerometer data were measured at the driver's seat, the front axle, and the rear-rear axle. These results showed the following features.

1. The longitudinal vibration at the driver's seat seemed to come from the front axle longitudinal vibration and also seemed to be amplified. The longitudinal vibration had a dominant fourthorder component of the wheel rotational frequency and also a smaller second-order component.

2. The vertical vibration at the driver's seat seemed to be attenuated as it passes through the frame and body structure in that the vibration at the front axle seemed to have a large amplitude below the fourth-order component of wheel rotational frequency, whereas the driver's seat vibration amplitude was relatively small.

3. There is a strong correlation between rear axle vibration and the driver's seat vibration in the longitudinal direction. The fourth-order component of the wheel rotational frequency was dominant and the second-order component was still evident.

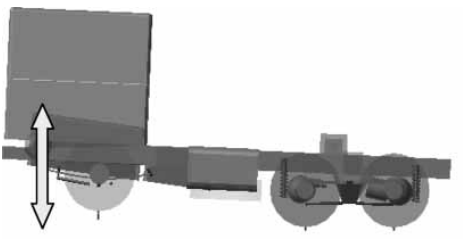

a. Front body bouncing motion

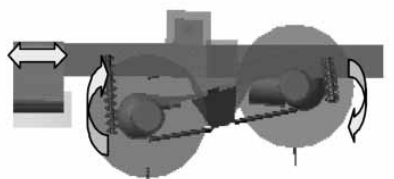

c. Walking motion of the rear tandem axle

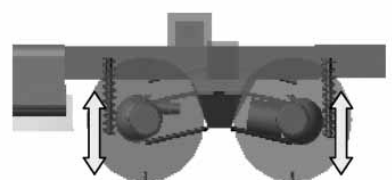

e. Vertical motion of the rear tandem axie

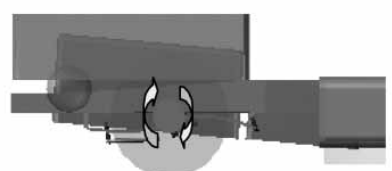

g. Wind-up motion of the front leaf spring

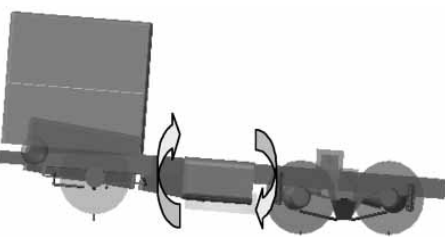

b. Vehicle body pitching motion

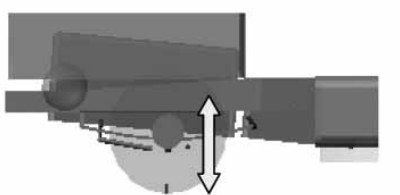

d. Vertical motion of the front axle

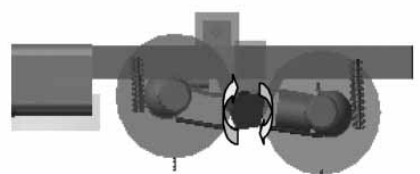

f. Wind-up motion of the rear leaf spring

Fig. 8 Mode shapes related to the low-frequency vibration (kerb weight) 
From the experimental data reported by Kim [5], the following features are considered to support the predicted results from the multi-body dynamics analysis presented here.

1. The main direction of the driver's seat vibration is longitudinal, not vertical.

2. The longitudinal vibration at the driver's seat seems to be affected by both front and rear axle vibrations.

3. The dominant frequency component of the driver's seat vibration is the fourth-order harmonic component of the wheel rotational frequency.

4. The vertical vibration at the driver's seat seems to be considerably attenuated by the vehicle chassis system.

\section{CONCLUSIONS}

Using multi-body dynamic modelling and simulation, the transmission of vibration in the form of judder from the brakes of a commercial vehicle to the cab and driver has been investigated. Predicted vibration response at the driver's seat was found to be a relevant and useful indicator of the perception of brake judder.

BTV-related modes such as front leaf spring windup and the rear axle assembly walking mode are associated with longitudinal vibration modes of the vehicle. This in turn indicates that the transmission of vibration arising from brake judder is predominantly longitudinal, i.e. along the chassis structure of the vehicle.

The mode shapes and natural frequencies showed that the longitudinal motions of the vehicle model were affected by the rear tandem axle movements in the judder-related frequency ranges of the vehicle. Since the characteristics of the tandem axle movement depend on the design of the axle and suspension assembly, this suggests that the axle/ suspension design can affect the driver's perception of brake judder and also that the transmission of brake judder vibration from the wheels to the cab and driver could be controlled by the design of the axle and suspension assembly.

\section{ACKNOWLEDGEMENT}

The authors wish to thank the Directors of the Hyundai Motor Company for providing the data and permission to publish this work.

\section{REFERENCES}

1 Fieldhouse, J. D. Brake noise, vibration and judder. In Braking of road vehicles 2005 (Eds A. J. Day and B. R. Shilton), 2005, pp. 301-320 (University of Bradford, Bradford).

2 de Vries, A. and Wagner, M. The brake judder phenomenon. SAE paper 920554, 1992.

3 Gassmann, S. and Engel, H. G. Excitation and transfer mechanism of brake judder. SAE paper 931880, 1993.

4 Kim, M. G., Jeong, H. I., and Yoo, W. S. Sensitivity analysis of chassis system to improve shimmy and brake judder vibration on steering wheel. SAE paper 960734, 1996.

5 Kim, H. S., Kim, C. B., and Yim, H. J. Robust design for a brake judder of heavy duty trucks using design for six sigma. SAE paper 2003-01-0882, 2003.

6 Abdelhamid, M. K. Brake judder analysis: case studies. SAE paper 972027, 1997.

7 Abdelhamid, M. K. Brake judder analysis using transfer functions. SAE paper 973018, 1997.

8 Jacobsson, H. Analysis of brake judder by use of amplitude functions. In Proceedings of SAE Noise and Vibration Conference, Traverse City, Michigan, pp. 2879-2892, SAE paper 1999-01-1779, 1999.

9 Jacobsson, H. Aspects of disc brake judder. Proc. Instn Mech. Engrs, Part D: J. Automobile Engineering, 2003, 217, 419-430.

10 Rahnejat H., Multibody dynamics: vehicles, machines and mechanisms, 1998 (Professional Engineering Publications (London) and Society of Automotive Engineers, Warrendale).

11 Blundell, M. V. and Harty, D. The multibody systems approach to vehicle dynamics, 2004 (Elsevier, Oxford).

\section{BIBLIOGRAPHY}

ADAMS/View User Guide Manual, 2003. 